\title{
Faktor-Faktor yang mempengaruhi Kepuasan Konsumen dan Kaitannya Dengan Kesetiaan Merek pada Produk Kesehatan K-Link di Kota Banda Aceh
}

\author{
Syamsul Rizal \\ Akademi Keuangan dan Perbankan (AKUBANK) Nusantara Aceh Timur
}

\begin{abstract}
Abstrak. Tujuan penelitian ini adalah untuk mengetabui mengetabui faktor-faktor kepuasan konsumen dan berapa besar pengarubnya terbadap kesetiaan merek pada produk makanan kesehatan K-link di Kota Banda Aceh. Objek Penelitian adalah tentang kepuasan dan kesetiaan merek, konsumen pada produk. makananan kesehatan K-Link di Kota Banda Aceh dengan jumlah sampel sebanyak. 250 responder. Hasil penelitian ini menunjukean bahwa terdapat bubungan (koefisien korelasi) yang cukup kuat antara variabel faktor-faktor kepuasan konsumen yang meliputi atribut produk, atribut pelayanan dan atributpembelian terbadap kesetiaan merek yaitu sebesar 0.649 atau 64.9\%. Hasil penelitian juga menunjuk.kan babwa ketiga variabel kepuasan konsumen mempunyai pengaruh yang cukup kuat terhadap kesetiaan merek produk makanan kesehatan K-link yaitu sebesar 0.422 atan 42.2\%. Variabel atribut produk mempunyai pengaruh dominan dalam mempengarubi kesetiaan merek konsumen pada produk makanan kesehatan K-Link, karena variabel ini mempunyai koefisien regresi lebib tinggi dibandingkan dua variabel independen lainnya.
\end{abstract}

Kata kunci: Kepuasan Konsumen, Kesetiaan, Merek, Produk. Kesehatan K-Link.

\begin{abstract}
The purpose of this study was to determine the factors of consumer satisfaction and how much influence on brand loyalty in K-link, health food products in the city of Banda Aceb. The object of research is about the satisfaction and loyalty of consumer brands in K-Link health food products in Banda Aceh City with a total sample of 250 respondents. The results of this study indicate that there is a significant correlation (correlation coefficient) between the variables of customer satisfaction factors that include product attributes, service attributes and purchase attributes to brand loyalty that is equal to 0.649 or $64.9 \%$. The results also showed that the three variables of consumer satisfaction had a strong influence on brand loyalty of $K$ link health food products that was 0.422 or $42.2 \%$. The product attribute variable has a dominant influence on influencing consumer brand loyalty on K-Link health food products because this variable has a higher regression coefficient than the other two independent variables.
\end{abstract}

Keywords: Consumer Satisfaction, Loyalty, Brand, K-Link Health Products. 


\section{Pendahuluan}

Perkembangan masyarakat modern ditandai dengan aktivitas kerja yang tinggi. Rutinitas kesibukan yang dihadapi beberapa kalangan masyarakat tersebut membuat mereka kesulitan meluangkan waktu untuk perduli terhadap kesehatan, padahal kesehatan sangat penting dalam menunjang aktivitas. Mereka yang sehat adalah mereka yang tidak terserang penyakit, sehat jasmani dan rohani, sehat ekonomi, sehat akhlaq dan lain sebagainya. Bahkan pengertian kesehatan itu telah memiliki standar internasional yang ditetapkan oleh World Health Organization (WHO), yaitu Kesehatan adalah suatu kondisi sejahtera jasmani rohani serta sosial ekonomi. Untuk menjaga kesehatan tubuh, kita memerlukan makanan yang bergizi guna meningkatkan kebugaran. Makanan dan kebugaran sangat berkaitan erat dengan pola makan bergizi dan aktivitas fisik yang teratur seperti olahraga. Makan makanan yang bergizi berarti makanan yang kita konsumsi bernutrisi seimbang sehingga dapat memelihara kesehatan tubuh, namun tidak berlebihan. Selain itu gaga hidup pun harus diperbaiki dengan meningkatkan aktivitas seperti berolahraga secara rutin dan istirahat yang cukup agar tubuh tetap sehat dan prima sampai usia senja, salah satu perusahaan yang memiliki produk kesehatan yang cukup dikenal masyarakat Kota Banda Aceh adalah K-Link.

K-Link kini telah dilengkapi dengan konsep visi yang luas dan pengurusan profesional yang bertujuan untuk mewujudkan tahap kehidupan dan budaya yang lebih sehat untuk masyarakat. Hingga kini kehadiran K-Link mendapat sambutan yang menggembirakan dan para penggunanya. hal ini dilihat dari mitra K-Link yang terus meningkat sepanjang perkembangannya. Fungsi sesuatu produk tidak lagi merupakan fokus utama bagi perusahaan karena kini fokus lebih diberikan kepada bentuk dan citra sesuatu produk. Produk-produk yang didistribusikan oleh PT K-Link melalui para distributornya adalah produk penjaga kesehatan, minuman kesehatan, dan makanan kesehatan. Produk yang paling banyak diminati adalah produk makanan kesehatan. Makanan kesehatan K-Link atau kita kenal dengan suplemen merupakan pelengkap kebutuhan gizi sehari-hari. Suplemen tidaklah sama dengan obat-obatan kimia yang bisa menyembuhkan penyakit dengan cepat pada saat dikonsumsi.

Beberapa atribut yang berhubungan dengan produk, pelayanan, dan pembelian menjadi faktor-faktor penting yang mendorong konsumen membeli produk K-Link khususnya makanan kesehatan yang pada akhirnya akan memberikan kepuasan tersendiri bagi konsumennya. Hal yang tidak kalah pentingnya adalah bagaimana menciptakan kesetiaan konsumen terhadap merek pada produk yang dihasilkan perusahaan. Untuk menciptakan loyalitas konsumen terhadap merek maka kita perlu menciptakan kepuasan konsumen, karena siapa yang dapat menciptakan kepuasan konsumen dia akan mempengaruhi persepsi konsumen dan dia pula yang akan memenangkan persaingan, karena bagaimanapun loyalitas sangat dipengaruhi oleh harapan berbanding kenyataan yang diperolehnya. Tujuan Penelitian adalah; 1) Untuk mengetahui faktor-faktor kepuasan konsumen dan kaitannya dengan kesetiaan merek pada produk kesehatan K-link di Kota Banda Aceh, dan 2) Untuk mengetahui berapa besar pengaruh faktor-faktor kepuasan konsumen terhadap kesetiaan merek pada produk kesehatan K-link di Kota Banda Aceh.

\section{Literature Review}

\section{Pengertian kepuasan konsumen}

Kepuasan konsumen adalah konsep penting dalam konsep pemasaran dan penelitian konsumen. Oliver menyatakan dalam kutipan Peter dan Olson (2000:158), bahwa kepuasan mungkin paling mudah dimengerti jika digambarkan sebagai suatu evaluasi terhadap surprise yang melckat pada suatu pengakuisisian atau pengalaman mengkomsumsi. Intinya, kepuasan adalah rangkuman kondisi psikologis yang dihasilkan ketika emosi yang mengelilingi harapan yang tidak cocok dilipatgandakan oleh perasaan-perasaan yang terbentuk dalam konsumen tentang pengalaman pengkonsumsian. Definisi kepuasan menurut Kotler (2000:36) adalah perasaan senang atau kecewa seseorang yang berasal dari perbandingan antara kesannya terhadap kineda (hasil) suatu produk dan harapannya. Tjiptono dan Chandra (2005:195), menyatakan bahwa kepuasan bisa diartikan sebagai upaya pemenuhan sesuatu atau membuat sesuatu 
memadai. Mowen dan Minor (2002:89) mendetinisikan bahwa kepuasan konsumen adalah keseluruhan sikap yang ditunjukkan konsumen atas barang atau jasa setelah mereka memperoleh dan menggunakannya. Jadi kepuasan konsumen pada dasarnya mencakup perbedaan antara harapan dan kinerja atau basil yang dirasakan oleh konsumennya. Kepuasan pelanggan ini sangat penting diperhatikan oleh perusahaan sebab berkaitan langsung dengan keberhasilan pemasaran dan penjualan produk perusahaan. Dengan demikian, kunci keberhasilan perusahaan sangat tergantung pada suksesnya perusahaan dalam memnaskan kebutuhan pelanggan.

\section{Atribut kepuasan}

Menurut Dutka (1994:41), atribut-atribut dari kepuasan konsumen secara umum mencakup pada tiga komponen diantaranya, produk. pelayanan, dan pembelian. Berikut ini adalah penjelasan mengenai atribut yang dimaksud.

a. Atribut Produk.

Kotler dan Armstrong (2007:199) mendefinisikan produk sebagai "Anything that can be offered to a market for attention, acquisition, use or consumption that might satisfy a want or need". Maksudnya adalah segala sesuatu yang dapat ditawarkan ke suatu pasar untuk memenuhi keinginan atau kebutuhan. Koller (2000:448) menyatakan bahwa produk adalah elemen kunci dalam tawaran pasar (market offering). Dalam hal ini produk dianggap sangat penting sebagai elemen pertarna dan yang paling penting dari bauran pemasaran.

Peter dan Olson (2000:171) juga menambahkan beberapa karakteristik yang penting dipertimbangkan dalam menganalisis hubungan konsumen dan produk Sebagian dari karakter tersebut telah terbukti dapat mempengaruhi keberhasilan suatu produk atau merek. Menurut Simamora (2000:540), produk sangat berhasil memusatkan perhatian pada kebutuhan pelanggan yang telah ditentukan dengan baik. Sebagian besar produk yang berhasil berkembang melalui suatu proses penemuan apa keistimewaan spesifik anggota pasar sasaran yang paling penting atau dapat diterima. Atribut produk menurut Dutka (1994:4I) adalah sebagai berikut:

1. Hubungan harga dengan nilat, merupakan faktor central dalam menentukan kepuasan konsumen, apabila nilai yang diperoleh konsumen melebihi apa yang dibayar, maka suatu dasar penting dari kepuasan konsumen telah tercipta.

2. Kualitas produk, merupakan penilaian dari suatu mutu produk.

3. Manfaat produk, merupakan manfaat yang dapat diperoleh konsumen dalam menggunakan suatu produk yang dihasilkan oleh suatu perusahaan dan kemudian dapat dijadikan dasar positioning yang membedakan perusahaan tersebut dengan perusahaan lainnya.

4. Cin khas produk, merupakan ciri-ciri tertentu yang dimiliki oleh suatu produk schingga berbcda dengan produk yang ditawarkan pesaing.

5. Desain produk, merupakan proses untuk merancang gaya dan fungsi produk yang menarik dan bermanfaat.

6. Kehandalan produk, merupakan keakuratan dan kehandalan produk yang dihasilkan oleh suatu perusahaan dalam jangka waktu tertentu dan menunjukkan pengiriman produk pada suatu tingkat kinerja khusus.

7. Jajaran produk atau jasa layanan, merupakan macam dari produk/jasa layanan yang ditawarkan perusahaan kepada konsumen.

b. Atribut Pelayanan

Adapun pengertian pelayanan menurut Kotler dan Armstrong (2007:199) adalah "any activity or benefit that one party can offer to another is essentially intangible and does not result in the ownership of anything". Ini berarti pelayanan merupakan suatu kegiatan atau manfaat yang ditawarkan oleh suatu pihak pada pihak lain dan pada dasamya tidak berwujud, serta tidak menghasilkan kepemilikan sesuatu, proses produksinya bisa mungkin dim hisa juga tidak mungkin dikaitkan dengan suatu produk fisik.

Berikut beberapa atribut pelayanan menurut Dutka (1994:41) antara lain:

1. Penanganan Keluhan

Merupakan penanganan terhadap 
keluhan yang dilakukan oleh konsumen terhadap perusahaan.

2. Kemampuan Memecahkan Masalah

Merupakan kemampuan perusahaan dalam dalam memecahkan masalah yang dihadapi konsumen.

c. Atribut Pembelian

Engel et al (1994:31) menyebutkan bahwa pembelian dilakukan ketika konsumen memperoleh altematif yang dipilih atau pengganti yang dapat diterima bila perlu. Menurut Lamb, Hair, Mc Daniel (2001:266) pembelian baru adalah suatu situasi yang mensyaratkan pembelian suatu produk untuk pertama kalinya". Konsumen sebagai sasaran pemasaran produk perusahaan akan menentukan sendiri apa yang akan dibeli dan akan melakukan pemilihan akan suatu produk yang dipakai. Makin terbatasnya kemampuan membeli produk yang diinginkan, makin berhati-hati pula seseorang dalam memutuskan produk mana yang layak dibeli sesuai dengan kemampuannya untuk mencapai kepuasan yang maksimal.

Keinginan membeli (purchase intention) menurut Peter dan Olson (2000:315) adalah suatu rencana keputusan atau keinginan untuk membeli sebuah produk atau merek tertentu. Purchase Imemion (keinginan membeli) merupakan perilaku yang muncul sebagai respon terhadap objek. Purcluise intention juga merupakan minat pembelian ulang yang menunjukkan keinginan pelanggan untuk melakukan pemberlian ulang (Assael, 1998).

Menurut Kotler (2014:561) dikutip dari penelitian yang dilakukan Syamsul Rizal (2017: 69)dengan Judul Pengaruh Kepuasan Nasabah terhadap menggunakan Mobile Banking (MBanking pada Bank BCA Cabang Banda Aceh. Dimana Pelayanan dapat dirincikan dalam 5 macam, yang terdiri dari 1) Keandalan(reability), 2) Responsifitas(responsive), 3) Keyakinan (confidance), 4) Empati (emphaty), dan 5) Berwujud (tangible).

\section{Pengukuran Kepuasan Konsumen}

Ada beberapa metode yang bisa digunakan untuk mengukur dan memantau kepuasan pelanggannya dan pelanggan pesaing. Kotler (2004) dalam kutipan Tjiptono dan Chandra (2005:210) mengidentilikasi empat metode untuk mengukur kepuasan pelanggan, antara lain:

1. Sistem Keluhan Dan Saran

2. Belanja Shuman (Ghost Shopping)

3. Analisa Kehilangan Pelanggan Customer Analis)

4. Survei Kepuasan Pelanggan Mowen dan Minor (2002:100) juga menambahkan, pengukuran tradisional atas kepuasan konsumen menilai evaluasi keseluruhan masyarakat akan prcduk, Berta evaluasi mereka atas atribut khusus. Skala liken Bering digunakan untuk tujuan ini: suatu pernyataan dibuat dan konsumen diminta untuk menunjukkan tingkat kesepakatan mereka dengan mengisi kuisioner.

\section{Pengertian Merek}

Nick Graham, President and Chief Underpants Officer, Joe Boxer dalam kutipan Gobe (2005:194) menyatakan bahwa merek adalah taman hiburan, dan produk adalah suvenimya. Kehadiran merek adalah suatu ilmu mengenai menciptakan atau menyebarkan pengaruh identitas merek dengan cara menghubungkannya dengan beragam konsumen nasional dan intemasional melalui penggunaan stimulan visual/emosional yang tepat pada berbagai poin dari pengalamannya.

Kotler dan Susanto (2001:574) mendefinisikan merek sebagai " istilah, tanda, symbol, atau rancangan, atau kombinasi dari hal-hal tersebut, yang dimaksudkan untuk mengidentitikasi barang atau jasa dari seorang atau sekelompok penjual dan untuk membedakannya dan produk pesaing. Gobe (2005:194) juga menambahkan hahwa merek memiliki berbagai macam kepribadian. Sebuah merek harus selalu berubah agar dapat menjaga hubungan dengan konsumennya dan momen-momen keberadaan mereka demi membangun dan mempertahankan din sebagat merek yang selalu ada dalam pikiran konsumen. Ekuitas merek terdiri dari lima komponen valtu; loyalitas merek (brand loyalty), kesadaran merek (brand awareness), mutu yang dirasakan (perceived quality), asosiasi merek (brand association), dan asset merek swamilik lain seperti paten. merek dagang dan saluran distribusi. 


\section{Loyalitas Konsumen}

Menurut Mittal dan Sheth (2004) dalam kutipan Tjiptono (2005: 387), loyalitas pelanggan adalah komitmen pelanggan terhadap suatu merek. toko, atau pemasok, berdasarkan sikap yang sangat positif dan tercermin dalam pembelian yang konsisten. Sementara itu, Bendapudi dan Berry (1997) dalam kutipan Tjiptono (2005: 387). Griffin (2003:222) menyebutkan bahwa pelanggan yang loyal adalah mereka yang sangat puas dengan produk atau jasa tertentu sehingga mempunyai antusiasme untuk memperkenalkannya kepada siapapun yang mereka kenal. Loyalitas konsumen dapat dikelompokan ke dalam dua kelompok yaitu loyalitas merek (brand loyalty) dan loyalitas toko (store loyalty), (Setiadi, 2003:199).

Salah satu konsep yang sangat penting dari sudut pandang strategi pemasaran adalah kesetiaan merek (brand loyalty). Terdapat dua pendekatan yang bisa dipakai untuk mempelajari loyalitas merek yaitu pendekatan instrumental conditioning (behavioral) dan pendekatan kognitif. Pendekatan behavioral menekankan bahwa loyalitas dibentuk oleh perilaku, dan oleh karena itu perilaku pembelian berulang adalah loyalitas, sementara itu pendekatan kognitif memandang bahwa loyalitas merek merupakan fungsi dari proses psikologi (decion makir).

Terdapat beberapa karakteristik umum untuk mengidentifikasi apakah seorang konsurnen mendekati loyalitas atau tidak. Assael (1992) dalam kutipan Setiadi (2003:201) mengemukakan empat hal yang menunjukkan kecenderungan konsumen yang loyal sebagai berikut:

1. Konsumen yang loyal terhadap merek cenderung lebih percaya dirt terhadap pilihannya.

2. Konsumen yang loyal memungkinkan merasakan tingkat resiko yang lebih tinggi dalam tingkat pembelian.

3. Konsumen yang loyal terhadap merek juga lebih mungkin loyal terhadap toko.

4. Kelompok konsumen yang minoritas cenderung untuk lebih loyal terhadap merek.

\section{Metodologi Penelitian}

\section{Peralatan Analisis Data}

Variabel tidak bebas (Y) adalah kesetiaan merek yang diukur melalui atribut kebiasaan, komitmen, percaya diri, resiko harga tinggi, dan rekomendasi. Variabel bebas (X) adalah kepuasan konsumen yang dikelompokkan menjadi atribut produk (X1), atribut pelayanan (X2), dan atribut pembelian (X3). Secara sistematis menurut Supranto (2004: 57), bentuk formulasi regresi linier berganda yang secara umum adalah sebagai berikut:

\begin{tabular}{|c|c|c|}
\hline \multirow{2}{*}{\multicolumn{3}{|c|}{$Y=a+b 1 X 1+b 2 X 2 b 3 X 3+e$}} \\
\hline & & \\
\hline Y & $=$ & Kesetiaan merek \\
\hline $\mathrm{a}$ & $=$ & Konstanta \\
\hline $\mathrm{X} 1$ & $=$ & Atribut produk \\
\hline $\mathrm{X} 2$ & $=$ & Atribut pelayanan. \\
\hline X 3 & $=$ & Atribut pembelian ian \\
\hline b 1 & $=$ & Koefisien regresi $\mathrm{Y}$ dengan $\mathrm{X} 1$ \\
\hline b 2 & $=$ & Koefisien regresi $\mathrm{Y}$ dengan $\mathrm{X} 2$ \\
\hline 2 & $=$ & Koefisien regresi $\mathrm{Y}$ dengan $\mathrm{X} 3$ \\
\hline & $=$ & Error \\
\hline
\end{tabular}

Untuk mengukur seberapa besar keeratan hubungan diantara variabel dependen $\mathrm{Y}$ dengan variabel independent $\left(\mathrm{X}_{1}, \mathrm{X}_{2}, \mathrm{X}_{3}\right)$ digunakan analisis Koefisien Linear Berganda (KLB).

\section{Pengujian Hipotesis}

Pengujian hipotesis digunakan untuk mengetahui efek interaksi dan pengaruh variabel bebas (X) yang lebih dari satu, yaitu atribut produk, atribut pelayanan, serta atribut pembelian yang berpengaruh terhadap kesetiaan merek pada produk makanan kesehatan K-Link. Pengujian hipotesis dapat menggunakan uji statitik $f$ atau uji $F$ dimana perumusannya sebagai berikut :

Ho $=$ Diduga variabel faktor-faktor kepuasan konsumen yang meliputi atribut produk, atribut pelayanan, dan atribut pembelian tidak memiliki pengaruh possitif yang signifikan terhadap kesetiaaan merek pada produk makanan kesehatan K-Link di kota Banda Aceh.

$\mathrm{Ha}=$ Diduga terdapat pengaruh positif yang signifikan antara variabel factor-faktor kepuasan konsumen yang meliputi atribut produk, atribut pelayanan, dan atribut pembelian terhadap kesetiaan merek pada produk makanan kesehatan K-Link di kota Banda Aceh. 
Sedangkan untuk pengujian secara individual (parsial) digunakan uji statistik distribusi t atau uji $\mathrm{t}$ dengan perumusan hipotesis sebagai berikut:

Ho1 : Diduga variabel atribut produk tidak memiliki pengaruh terhadap kesetiaaan merek pada produk makanan kesehatan K-Link di kota Banda Aceh.

Ha1 : Diduga terdapat pengaruh positif yang signifikan antara variabel atribut produk terhadap kesetiaan merek pada produk makanan kesehatan K-Link di kota Banda Aceh.

$\mathrm{Ho}_{2}$ : Diduga variabel atribut pelayanan tidak memiliki pengaruh terhadap kesetiaaan merek pada produk makanan kesehatan K-Link di kota Banda Aceh.

$\mathrm{Ha}_{2}$ : Diduga terdapat pengaruh positif yang signifikan antara variabel atribut pelayanan terhadap kesetiaan merek pada produk makanan kesehatan K-Link di kota Banda Aceh.

Ho3 : Diduga variabel atribut pembelian tidak memiliki pengaruh terhadap kesetiaaan merek pada produk makanan kesehatan K-Link di kota Banda Aceh.

Ha3 : Diduga terdapat pengaruh positif yang signifikan antara variabel atribut pembelian terhadap kesetiaan merek pads produk makanan kesehatan K-Link di kola Banda Aceh.

Untuk menguji hipotesis dalam penelitian ini penulis menggunakan uji F'tabel dan uji Ttabel yaitu pads tingkat keyakinan 95\% atau tingkat kesalahan (alpha) a sebesar 0,05:

1. Jika t-hitung $>\mathrm{t}$-tabel, maka Ha diterima

2. Jika t-hitung $<\mathrm{t}$-tabel, maka Ha ditolak

3. Jika F-hitung $>$ F-tabel, maka Ha diterima

4. Jika F-hitung $<$ F-tabel, maka $\mathrm{H}$, ditolak.

\section{Hasil dan Pembahasan}

Berdasarkan Tabel 2 memperlihatkan bahwa alpha untuk masing-masing variabel penelitian yaitu Kesetiaan Merek (Y) diperoleh nilai alpha sebesar 73.8\%, Atribut Produk (Xi) diperoleh nilai alpha sebesar $80.8 \%$, Atribut Pelayanan (X2) diperoleh nilai alpha sebesar 74.6\%, Atribut Pembelian (X3) diperoleh nilai alpha sebesar $81.3 \%$. Pengukuran reliabilitas terhadap variabel penelitian menunjukkan bahwa pengukuran kehandalan memenuhi persyaratan yang dipersyaratkan diatas 0.60 atau $60 \%$.

Tabel 1. Hasil Uji Validitas

\begin{tabular}{crc}
\hline $\begin{array}{c}\text { Item } \\
\text { Pertanyaan }\end{array}$ & $\begin{array}{c}\text { Koefisien } \\
\text { Korelasi }\end{array}$ & $\begin{array}{c}\text { Mai Kritis } \\
(\mathrm{N}=250)\end{array}$ \\
\hline A1 & 0.641 & 0.138 \\
A2 & 0.715 & 0.138 \\
A3 & 0.727 & 0.138 \\
A4 & 0.752 & 0.138 \\
A5 & 0.701 & 0.138 \\
B1 & 0.532 & 0.138 \\
B2 & 0.785 & 0.138 \\
B3 & 0.659 & 0.138 \\
B4 & 0.773 & 0.138 \\
B5 & 0.773 & 0.138 \\
B6 & 0.762 & 0.138 \\
C1 & 0.731 & 0.138 \\
C2 & 0.742 & 0.138 \\
C3 & 0.684 & 0.138 \\
C4 & 0.711 & 0.138 \\
C5 & 0.702 & 0.138 \\
DI & 0.693 & 0.138 \\
D2 & 0.733 & 0.138 \\
D3 & 0.786 & 0.138 \\
D4 & 0.806 & 0.138 \\
D5 & 0.762 & 0.138 \\
\hline
\end{tabular}

Sumber : Data Primer, 2020 (diolah)

Tabel 2. Reliabilitas Variabel Penelitian

\begin{tabular}{lllll}
\hline No $\quad$ Variabel & $\begin{array}{c}\text { Rata- Jumlah } \\
\text { rata }\end{array}$ & $\begin{array}{c}\text { Nilai } \\
\text { Variabel }\end{array}$ & Alpha & Ket \\
\hline I Kesetiaan Merek (Y) & 4.139 & 5 & 0.738 Handal \\
2 Atribut Produk (X1) & 4.228 & 6 & 0.808 Handal \\
3 Atribut Pelayanan (X2) & 3.745 & 5 & 0.746 Handal \\
4 Atribut Pembelian (X3) & 4.213 & 5 & 0.813 Handal \\
\hline Sumber : Data Primer, 2020 & (diolah) &
\end{tabular}

\section{Pembahasan}

Analisis ini untuk mengetahui pengaruh variabelvariabel kepuasan yaitu Atribut Produk (Xi), Atribut Pelayanan (X2) dan Atribut Pembelian (X3) terhadap kesetiaan merek $(Y)$ dapat dilihat pada Tabel 3 berikut ini. 
Tabel 3. Pengaruh masing-masing Variabel Bebas Terhadap variabel terikat

\begin{tabular}{|c|c|c|c|c|}
\hline Nama Variabel & 8 & $\begin{array}{l}\text { Standar } \\
\text { Error }\end{array}$ & $\mathrm{T}_{\text {hitung }}$ & $g \mathrm{~T}_{\text {tabel }}$ \\
\hline Konstanta & 1.131 & .232 & 4.881 & 1.96950 .000 \\
\hline Atribut Produk & .439 & .060 & 7.275 & 1.96950 .000 \\
\hline Atribut Pelayanan & .176 & .046 & 3.810 & 1.96950 .000 \\
\hline Atribut Pembelian & .117 & .058 & 2.035 & 1.96950 .043 \\
\hline
\end{tabular}

Sumber : Data Primer, 2020 (diolah)

Tabel 4. Tabel Model Summary

\begin{tabular}{ccccc}
\hline $\mathrm{R}$ & $\mathrm{R}$ square & Adjusted R $\mathrm{R}^{2} \begin{array}{l}\text { Std. Error of } \\
\text { the Estimate }\end{array}$ & Ket \\
\hline 0.649 & 0.422 & 0.415 & 0.419 & $\begin{array}{l}\text { Korelasi } \\
\text { sangat kuat }\end{array}$ \\
\hline
\end{tabular}

Sumber : Data Primer, 2020 (diolah)

Tabel 5. Anallisis of Variance (ANOVA)

\begin{tabular}{lrrrrrr}
\hline Model & $\begin{array}{c}\text { Sum of } \\
\text { Squares }\end{array}$ & Df & $\begin{array}{c}\text { Mean } \\
\text { Squares }\end{array}$ & Fhitung & F tabel & Sig. \\
\hline Regresi & 31.427 & 3 & 10.476 & 59.808 & $2-6413$ & 0.000 \\
Sisa & 43.089 & 246 & .175 & & & \\
Total & 74.516 & 249 & & & & \\
\hline
\end{tabular}

Sumber : Data Primer, 2020 (diolah)

\section{Hasil Uji-t}

Faktor-faktor kepuasan konsumen yang mempengaruhi kesetiaan merek konsumen pada produk makanan kesehatan k-link di kota Banda Aceh secara parsial dapat dilihat dari hasil uji t. Hasil perhitungan yang diperlihatkan menunjukkan besarnya t hitung untuk masingmasing variabel derajat signifikansi sebesar $\mathrm{a}=$ $5 \%$.

1. Variabel Atribut Produk (X1)

Hasil penelitian terhadap variabel atribut produk $(\mathrm{Xi})$ diperoleh nilai t hitung sebesar 7.275, sedangkan t tabel sebesar 1.9695 . Hasil perhitungan menunjukkan bahwa $t$ hitung $>$ t label dengan tingkat signifikansi 0.000. Dengan demikian hasil perhitungan statistik menunjukkan bahwa secara parsial variabel atribut produk berpengaruh secara signifikan (nyata) terhadap kesetiaan merek produk kesehatan K-link di kota Banda Aceh.

2. Variabel Atribut Pelayanan (X2)

Hasil penelitian terhadap variabel atribut pelayanan (X2) diperoleh nilai $t$ hazing sebesar 3.810, sedangkan t tabel sebesar 1.9695. Hasil perhitungan menunjukkan bahwa $\mathrm{t}$ hitung $>\mathrm{t}$ tahel dengan tingkat signifikansi 0.000. Dengan demikian hasil perhitungan statistik menunjukkan bahwa secara parsial variabel atribut pelayanan berpengaruh secara signifikan (nyata) terhadap kesetiaan merek pads produk kesehatan K-link di kota Banda Aceh.

3. Variabel Atribut Pembelian (X3)

Hasil penelitian terhadap variabel atribut pembelian (X3) diperoleh nilai $\mathrm{t}$ hitung sebesar 2.035, sedangkan t tabel sebesar 1.9695. Hasil perhitungan menunjukkan bahwa $\mathrm{t}$ hitung $>$ tabel dengan tingkat signifikansi 0.043. Dengan demikian hasil perhitungan statistik menunjukkan bahwa secara parsial variabel atribut pembelian berpengaruh secara signifikan (nyata) terhadap kesetiaan merek produk kesehatan K-link di kota Banda Aceh.

\section{Pembuktian Hipotesis}

Hasil pengolahan data memperlihatkan nilai $\mathrm{F}$ hitung sebesar 59.808 dan $F$ tabel pada signifikansi a $=5 \%$ adalah sebesar 2.6413. Hal tersebut menunjukkan bahwa secara menyeluruh/simultan variabel atribut produk, variabel atribut pelayanan dan variabel atribut pembelian secara bersama-sama berpengaruh secara signifikan terhadap kesetiaan merek produk kesehatan K-link di kota Banda Aceh.

Koefisien determinasi diperoleh nilai sebesar 0.422 , artinya sebesar $42.2 \%$ kesetiaan merek konsumen dipengaruhi oleh faktor atribut produk, atribut pelayanan dan atribut pembelian. Selebihnya sebesar 57.8\% dipengaruhi oleh faktor-faktor fain diluar tiga faktor seperti yang dijelaskan diatas.

Sedangkan secara parsial variabel yang diteliti adalah variabel kepuasan yang mempunyai pengaruh yang signifikan terhadap kesetiaan merek pada produk makanan kesehatan K-link di kota Banda Aceh yaitu atribut produk, atribut pelayanan dan atribut pembelian, ketiga variabel yang diteliti memiliki nilai thitung $>$ ttabel.

\section{Kesimpulan dan Saran}

Bedasarkan hasil analisis regresi tinier berganda diperoleh koefisien determinasi sebesar 0.422 , 
artinya sebesar $42.2 \%$ kesetiaan merek dipengaruhi oleh faktor atribut produk, faktor atribut pelayanan dan faktor atribut pembelian. Selebihnya sebesar $57.8 \%$ dipengaruhi oleh faktor-faktor lain diluar penelitian ini. variabel faktor-faktor kepuasan konsumen yang mempunyai pengaruh paling dominan terhadap kesetiaan merek adalah variabel atribut produk karma mempunyai nilai koefisien regresi lebih tinggi dibandingkan variabel lainnya. Diperoleh nilai ${ }^{F}$ hitung sebesar 59.808, sedangkan ${ }^{\mathrm{F}}$ tabel pada tingkat signifikan $a=5 \%$ adalah sebesar 2.6413. Hal ini memperlihatkan bahwa ${ }^{\mathrm{F}}$ hitung $>{ }^{\mathrm{F}}$ tabel., dengan tingkat signifikan 0.000. Dari hasil perhitungan ini dapat diambil suatu kesimpulan bahwa menerima hipotesis alternatif dan menolak hipotesis not, artinya bahwa faktorfaktor kepuasan konsumen yaitu variabel atribut produk, atribut pelayanan dan atribut pembelian secara bersama-sama berpengaruh secara signifikan terhadap kesetiaan merek pada produk makanan kesehatan K-Link di kola Banda Aceh. Berdasarkan hasil uji t (secara parsial) menunjukkan bahwa ketiga, variabel kepuasan konsumen yaitu atribut produk, atribut pelayanan dan atribut pembelian berpengaruh secara, signifikan terhadap kesetiaan merek pada produk makanan kesehatan K-Link di kota Banda Aceh, yaitu variabel atribut produk mempunyai nilai thitung $>$ ttabeldengan tingkat signifikansi $\mathrm{a}=$ 0.000 , variabel atribut pelayanan mempunyai nilai $\mathrm{t}$ hitung $>\mathrm{t}$ tabel dengan tingkat signifikansi $\mathrm{a}=0.000$, variabel atribut pembelian mempunyai nilai $\mathrm{t}$ hitung $>\mathrm{t}$ tabel dengan tingkat signifikansi $a=0.043$

\section{Daftar Pustaka}

Assael, H. (1998). Consumer behavior and marketing action. Boston: Wadsworth.

Dutka, A. (1994). AMA Hand book for Customer Satisfaction: A Complete Guidance to Research, Planning, and Implementation. International Edition, NTC Business Book, Lincolnwood, Illinois, USA.
Engel, James.F, Ronger D. Blackwell, Paul W. Miniard (1994) Perilaku konsumen. Edisi Empat. Jilid Satu, Jakarta :Bins Rupa Aksara.

Gobe. Marc (2005) Emotional Branding. Erlangga, Jakarta Griffin, Jill (2003) Customer Loyalty. Erlangga, Jakarta.

Kotler, dan Susanto, A.B (2001) Manajemen Pemasaran Di Indonesia. Salemba Empat, Jakarta.

Kotler, Philip (2000) Manajemen Pemasaran Edisi Milennium. Jilid Dua, Edisi Revisi Prehallindo, Jakarta.

Kotler, Philip and Armstrong, Gary (2007) Marketing An Introduction. Eigth Edition. New Jersey, Pearson Prentice Hall, Inc.

Lamb, Hair, Mc Daniel (2001) Pemasaran. Buku 1, Salemba Empat, Jakarta.

Mittal, B., \& Sheth, J. (2004). Customer Behavior: A managerial perspective. Natorp Boulevard: Thompson South Western.

Mowen, Jhon C And Minor, Michael (2002) Perilaku Konsumen. Jilid Dua, Edisi Lima, Erlangga, Jakarta.

Peter, J Paul And Olson, Jerry C (2000) Consumer Behaviour Perilaku Konsumen Dan Strategi Pemasaran. Edisi Empat, Jilid I \& 2, Erlangga, Jakarta.

Rizal, S., \& Munawir, M. (2017). Pengaruh Kepuasan Nasabah Terhadap Menggunakan Mobile Banking (MBanking) Pada Bank BCA Cabang Banda Aceh. Jurnal EMT KITA, 1(2), 68-78.

Setiadi, Nugroho J, SE.MM (2003) Perilaku Konsumen Konsep Dan Implikasi Untuk Strategi Dan Penelitian Pemasaran. Jakarta: Kencana. 
Simamora, Henry (2000) Manajemen Pemasaran Internasional. Jilid 2, Salemba Empat, Jakarta.

Supranto J. (2001) Pengukuran Tingkat Kepuasan Pelanggan, Untuk Menaikkan Pangsa Pasar, (Edisi Baru), Penerbit: Rineka Cipta, Jakarta.
Tjiptono, F. (2005). Brand management \& strategy. Yogyakarta: Andi.

Tjiptono, Fandi (2005) Pemasaran Jasa. Bayumedia, Surabaya. ,dan Chandra, Gregius (2005) Service, Quality, Satisfaction. Andi, Yogyakarta. 